\title{
Disposiciones generales de las Comunidades Autónomas (*)
}

\section{COLEGIOS PROFESIONALES}

CAS-15 Ley 10/2005, de 11 de octubre (Presidencia de la Comunidad Autónoma de Castilla y León).

Creación del Consejo de Colegios Profesionales de Administradores de Fincas de Castilla y León.

BOE núm. 264, de 4 de noviembre.

BOCL núm. 201, de 18 de octubre.

ARA-13 Ley 8/2005, de 10 de octubre Presidencia de la Comunidad Autónoma de Aragón).

Creación, por segregación, del Colegio Profesional de Doctores y Licenciados en Bellas Artes y Profesores de Dibujo de Aragón.

BOE núm. 269, de 10 de noviembre.

BOA núm. 127, de 26 de octubre.

ARA-14 Ley 8/2005, de 10 de octubre (Presidencia de la Comunidad Autónoma de Aragón).

Creación del Colegio Profesional de Educadoras y Educadores Sociales de Aragón.

BOE núm. 269, de 10 de noviembre.

BOA núm. 127, de 26 de octubre.

VAL-11 Ley 7/2005, de 18 de noviembre (Presidencia de la Generalitat valenciana).

Creación del Colegio Oficial de Ingenieros Técnicos en Informática.

BOE núm. 310, de 28 de diciembre.

DOCV núm. 5142, de 24 de noviembre.

VAL-12

Ley 8/2005, de 18 de noviembre (Presidencia de la Generalitat valenciana).

(*) Sección elaborada por JUAN ANTONIO CARRILLO DONAIRE. Comprende las leyes y normas con rango de ley de las Comunidades Autónomas publicadas en el BOE durante el cuarto y último trimestre de 2005 (X-XII). 
Creación del Colegio profesional de de Higienistas Dentales.

BOE núm. 310, de 28 de diciembre.

DOCV núm. 5142, de 24 de noviembre.

CAT-13 Ley 9/2005, de 18 de noviembre (Presidencia de la Generalitat valenciana).

Creación del Colegio Oficial de Ingenieros Químicos.

BOE núm. 310, de 28 de diciembre.

DOCV núm. 5142, de 24 de noviembre.

\section{COMERCIO}

ARA-15 Ley 7/2005, de 4 de octubre (Presidencia de la Comunidad Autónoma de Aragón).

Horarios comerciales y apertura de festivos.

BOE núm. 264, de 4 de noviembre.

BOA núm. 124, de 20 de octubre.

VAL-14 Ley 6/2005, de 18 de octubre (Presidencia de la Generalitat valenciana).

Modifica la Ley 8/1997, de 9 de diciembre, de horarios comerciales.

BOE núm. 292, de 7 de diciembre.

DOCV núm. 5118, de 20 de octubre.

\section{CONCENTRACIONES PARCELARIAS}

\section{CAS-16}

Ley 11/2005, de 24 de noviembre (Presidencia de la Comunidad Autónoma de Castilla y León).

Modificación global de la Ley 14/1990, de 28 de noviembre, de concentración parcelaria.

BOE núm. 303, de 20 de diciembre.

BOCL núm. 233, de 2 de diciembre.

\section{CONSEJO ECONÓMICO Y SOCIAL}

RIO-9 Ley 10/2005, de 30 de septiembre (Presidencia de la Comunidad Autónoma de La Rioja). 
Modifica parcialmente la Ley 6/1997, de 18 de julio, reguladora del Consejo Económico y Social de La Rioja.

BOE núm. 252, de 21 de octubre.

BOR, núm. 132, de 6 de octubre.

\section{CONTAMINACIÓN LUMÍNICA}

NAV-15 Ley Foral 10/2005, de 9 de noviembre (Presidencia de la Comunidad Foral de Navarra).

Ordenación del alumbrado para la protección del medio nocturno.

BOE núm. 304, de 21 de diciembre.

BON núm. 136, de 14 de noviembre.

\section{ESTADÍSTICA}

DRC-5 Ley 4/2005, de 5 de octubre (Presidencia de la Comunidad

Estadística.

BOE núm. 267, de 8 de noviembre.

BOC núm. 198, de 17 de octubre.

\section{HACIENDA PÚBLICA}

BAL-11 BAL-15 Decreto Legislativo 1/2005, de 24 de junio (Presidencia del Gobierno de las Islas Baleares).

Texto refundido de la Ley de Finanzas de la Comunidad Autónoma de las Illes Balears.

BOE núm. 240, de 7 de octubre.

BOIB, núms. 98 y 104, de 28 de junio y 12 de julio.

VIII. I+D

CAT-16 Ley 12/2005, de 17 de noviembre (Presidencia de la Generalitat de Catalunya).

Nueva regulación del Centro de Innovación y Desarrollo Empresarial (CIDEM).

BOE núm. 303, de 20 de diciembre.

DOGG núm. 4519, de 28 de noviembre. 


\section{OBRAS PÚBLICAS}

NAV-16 Ley Foral 12/2005, de 22 de noviembre (Presidencia de la Comunidad Foral de Navarra).

Construcción y explotación de las infraestructuras de interés general de la zona regable del Canal de Navarra.

BOE núm. 304, de 21 de diciembre.

BON núm. 141, de 25 de noviembre.

\section{ORDENACIÓN DEL TERRITORIO Y URBANISMO}

BAL-16 Ley 11/2005, de 7 de diciembre (Presidencia de la Comunidad Autónoma de las Islas Baleares).

Medidas específicas y tributarias para las islas de Ibiza y Formentera, en materia de ordenación territorial, urbanismo y turismo.

BOE núm. 310, de 28 de diciembre.

BOIB núm. 188, de 15 de diciembre.

\section{PATRIMONIO}

RIO-10

Ley 11/2005, de 19 de octubre (Presidencia de la Comunidad Autónoma de La Rioja).

Patrimonio de la Comunidad Autónoma de La Rioja.

BOE núm. 270, de 11 de noviembre.

BOR núm. 141, de 25 de octubre.

\section{XII.PATRIMONIO CULTURAL}

NAV-17 Ley Foral 14/2005, de 22 de noviembre (Presidencia de la Comunidad Foral de Navarra).

Patrimonio Cultural de Navarra.

BOE núm. 304, de 21 de diciembre.

BON núm. 141, de 25 de noviembre.

\section{RÉGIMEN LOCAL}

CAN-6

Ley 5/2005, de 11 de noviembre (Presidencia de la Comunidad Autónoma de Canarias). 
Integración del Cabildo Insular de La Palma en el régimen previsto en la Ley $57 / 2003$, de 16 de diciembre, de medidas para la modernización del gobierno local.

BOE núm. 292, de 7 de diciembre.

BOC núm. 228, de 21 de noviembre.

\section{SANIDAD}

RIO-11 Ley 9/2005, de 30 de septiembre (Presidencia de la Comunidad Autónoma de La Rioja).

Reguladora del documento de instrucciones previas en el ámbito de la sanidad.

BOE núm. 252, de 21 de octubre.

BOR núm. 132, de 6 de octubre.

MAD-8 Ley 3/2005, de 23 de mayo (Presidencia de la Comunidad Autónoma de Madrid).

Regula el ejercicio del derecho a formular instrucciones previas en el ámbito sanitario y se crea el registro correspondiente.

BOE núm. 269, de 10 de noviembre.

BOCM núm. 140, de 14 de junio.

\section{SUBVENCIONES}

NAV-18 Ley Foral 11/2005, de 22 de noviembre (Presidencia de la

Subvenciones

BOE núm. 304, de 21 de diciembre.

BON núm. 141, de 25 de noviembre.

\section{VÍAS PECUARIAS}

ARA-16 Ley 10/2005, de 11 de noviembre (Presidencia de la Comunidad

Vías pecuarias de Aragón.

BOE núm. 294, de 9 de diciembre.

BOA núm. 139, de 23 de noviembre. 